وصف الانهيار الانقلابي للمنحدرات على طريق بازيان-جمي ريزان، شمال شرقي العراق

فرج احمد السليمان

(تاريخ الاستلام 2018/8/14 تاربخ القبول 2018/10/8 )
محمود زكي عبدالقادر اوميد احمد محمد توكمجي

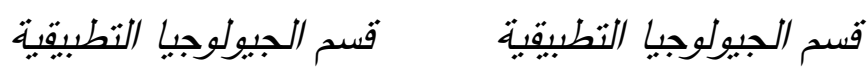

جامعة كركوك

كلية العلوم

جامعة كركوك
كلية العلوم

\title{
الملخص
}

تمنلت منطقة الدراسة بالمنحدرات المطلة على طول الطريق الرابط بين منطقني بازيان وجمي ريزان في

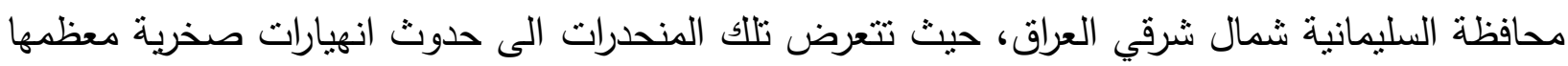
من نوع الانقلاب الصخري والتي تودي احيانا الى غلق ذللك الطريق. هدفت الدراسة الحالية الى اجراء دراسة

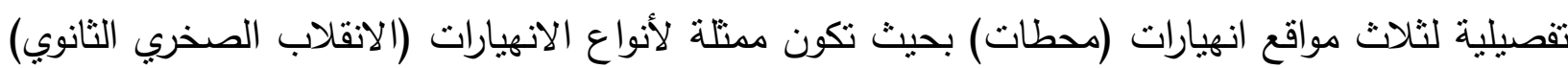

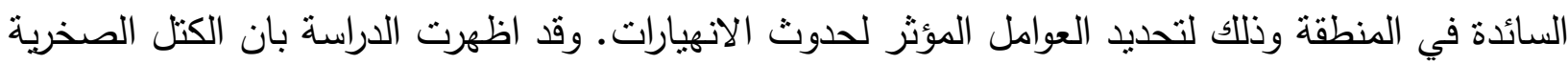

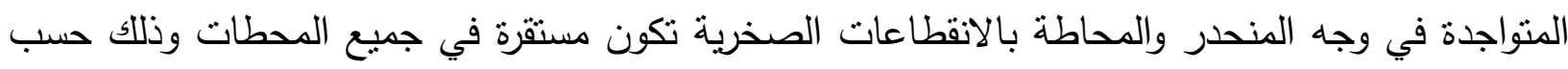
قواعد حدوث الانقلاب الصخري، الا انه تحدث الانهيارات بسبب تدخل عوامل اخرى من تجوية وتعرية التي

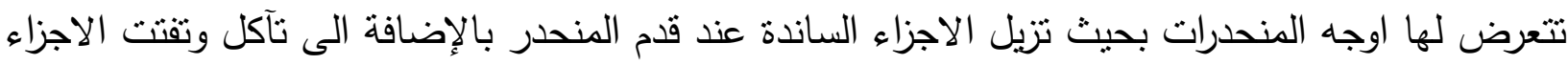

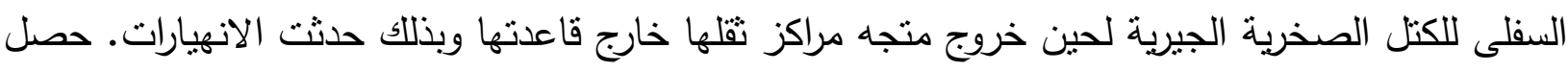

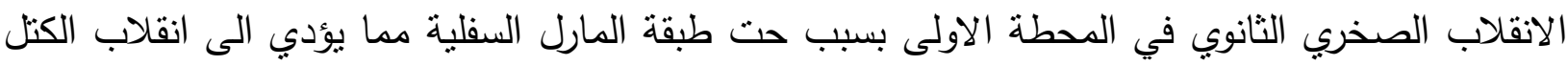

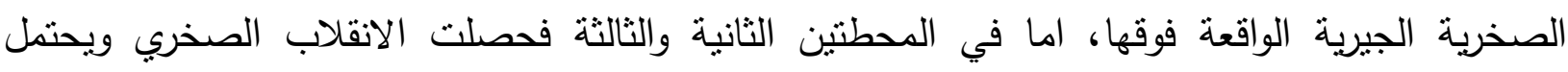
حصولها بسبب تجوية وتعرية الاجزاء القاعدية للكتل الصخرية الجيرية نفسها. الكلمات الدالة:الانهيار الانقلابي، الانقلاب الصخرية الإهاء بازيان، جمي ريزان، المنحدرات.

\section{Toppling Failure Qualify of Slopes on Bazian - ChamiRezanRoad, Northeastern Iraq}

Mahmood Z. Abdolqader

Department of Applied

Geology

University of Kirkuk
Aomed A. Tokmachy

Department of Applied

Geology

University of Kirkuk
Faraj A. AL-Sulaiman

North Oil Company

Kirkuk

Iraq 


\section{ABSTRACT}

The study area is represented by the slopes, which are found along the Bazian - Chami Rezan road in the Sulaimaniyah Governorate, northeastern Iraq. The slopes were exposed to rock failure mostly rock toppling that led sometimes to the closure of the road. The present study aims to conduct a detailed study of three sites of failure(stations) to be representative of the type of failure (secondary rock toppling) prevailing over the study area to determine the factors affecting the failure. The rock blocks located in the face of the slope that surrounded by discontinuities are stable in the area according to the rules of the rock toppling. The toppling occurs due to the intervention of other factors such as weathering and erosion which led to the remove of the supporting parts at the slope toe in addition to erosion and dissolution of the lower parts of the limestone until the exit of centers of gravity vector outside the base of rock mass. Thus, secondary rock toppling occurs either because of the undercutting such as in the station (1) or because of the weathering and erosion of the basal parts of the same limestone blocks such as in the stations ( 2 and 3 ).

Keywords:Toppling Failure, Rook Toppling, Bazian, Chimmi Rezan, Slopes.

\section{المقدمة}

تعد الهنحدرات واحدة من اهم الظواهر الجيولوجية وأكثرها انتشاراً على وجه الارض الصخرية، وتعد عدم استقرارية الكتلة الصخرية من ابرز المشاكل الجيولوجية الهندية التي تعاني منها تلك المنحدرات.

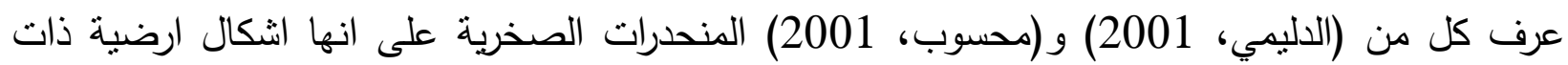
اوجه مائلة بدرجات معينة عن المستوى الافقي، من جانب اخر فقد عرف (محسوب، 2001) الانهيار

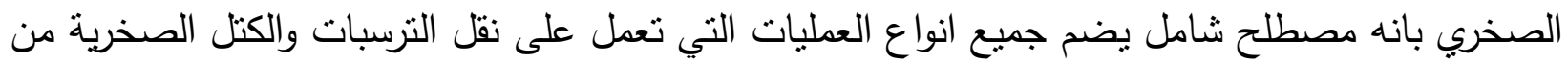

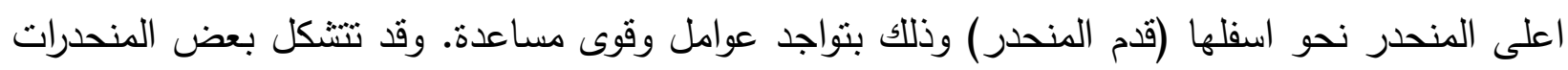

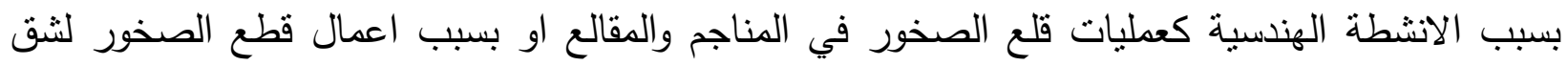
الطرق او حفر الانفاق او بناء السدود مما يؤدي الى فقدان الصخور لاعائمها الطبيعية ومن ثم انهيارها (محسوب، Wyllie and Mah, 2004، و 2001)، ولذلك بعتبر تحليل استقرارية المنحدرات الصخرية وتصنيف الانهيارات الصخرية الحاصلة والمتملة فيها وتحديد الاسباب المؤدية الى تلك ولك الانهيارات ووضع معالجات لها للحيلولة دون وقوع اضرار بالأرواح والممتلكات هي من الهم الدراسات الجيولوجية الهندسية. تهدف هذه الدراسة الى اجراء مسح جيولوجي هندسي لعدد من الهنحدرات الصخرية

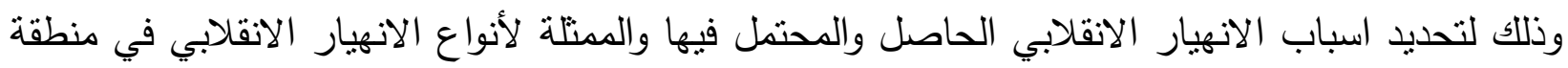
الدراسة، وتحديد الاسباب المؤدية لها ودور التباين الصخاري ووضعية الانقطاعات الصخرية وكذلك حجم الإنم الكتلة الصخرية في تحديد نمط الانقلاب الصخري. 
تقع منطقة الدراسة بين منطقتي بازبان وجمي ريزان والذي يربطهما طربق يبلغ طوله حولي (31 كم)

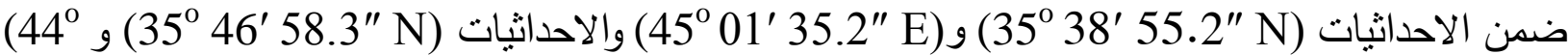
(58'42" E)

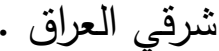

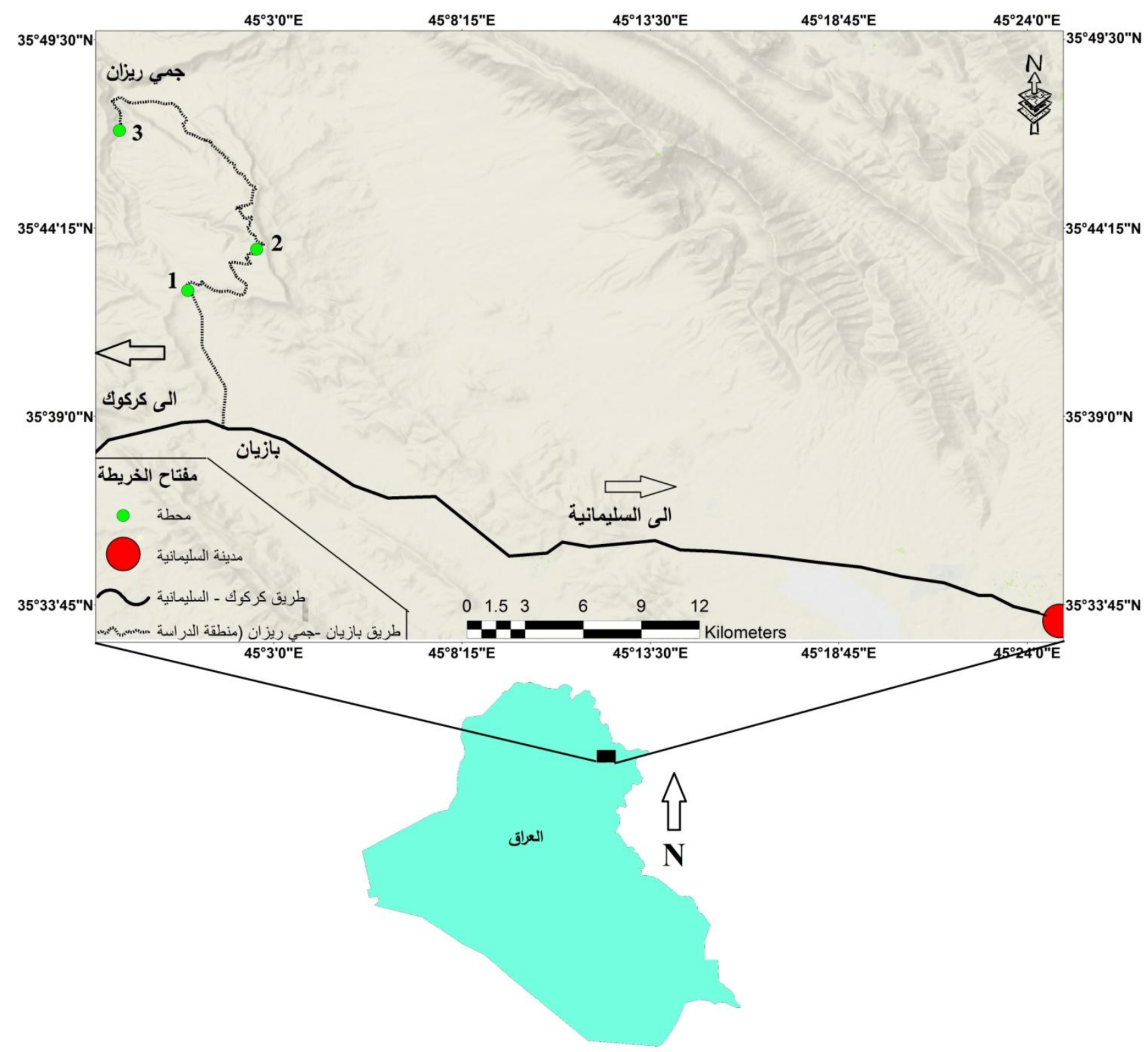

الشكل 1: الخارطة الموقعية لمنطقة الدراسة.

\section{جيولوجية منطقة الدراسة}

تقع منطقة الدراسـة من الناحية التكتونية ضمن نطاق الطيات العالية وذلك حسب الخربطة التكتونيـة لـ(Fouad, 2012)، امـا من الناحية التركيبية فأنها تقع في الجزء الثـمال الغربي لتركيب ميران والمكون 
اساساً من ثلاث طيات اثثتان منها محدبتان وهما طيتا ميران الغربية وميران الثرقية والاخرى مقعرة وهي طية طاسلوجة والتي تتوسط الطيتين المحدبتين (Al-Hakari, 2011). من الناحية الطباقية ينكثف في منطقة الدراسة تكوين كولوش ذو عمر الباليوسين (Paleocene) (Jassim and Goff, 2006).

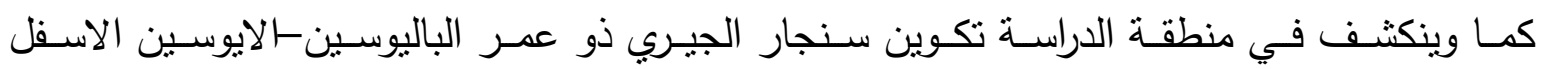
(Bellen et al., 1959) بسمك حوالي (100 متر ) ويتميز حده السفلي بأنه غير متوافق مع تكوين كولوش بينما يكون حده العلوي متوافقا مع تكوين جركس(Al-Hakari, 2011). بنكثف هذا التكوين على نطاق واسع في منطقة الدراسـة حيث يظهر على شكل صخور جيرية متعددة السحنات، وتمتاز صخور هذا التكوين بأنها ذات لون اصفر هري الى برتقالي وتكون شديدة التكسر (highly jointed) وذات درجـة تجويـة متغيرة من موقع لآخر وذات صلابة عالية، كما وتحوي صخور هذا التكوين على عروق من معدن الكالسايت وعقد الجيرت. واخيرا هنالك بعض المواقع في منطقة الدراسة تكون مغطاة بالترسبات الحديثة كما في (الثكل 2)، ومن الجدير بالإشـارة الى ان المحطات المختارة في هذه الدراسة كانت تقع جميعها على تكوين سنجار الجيري.

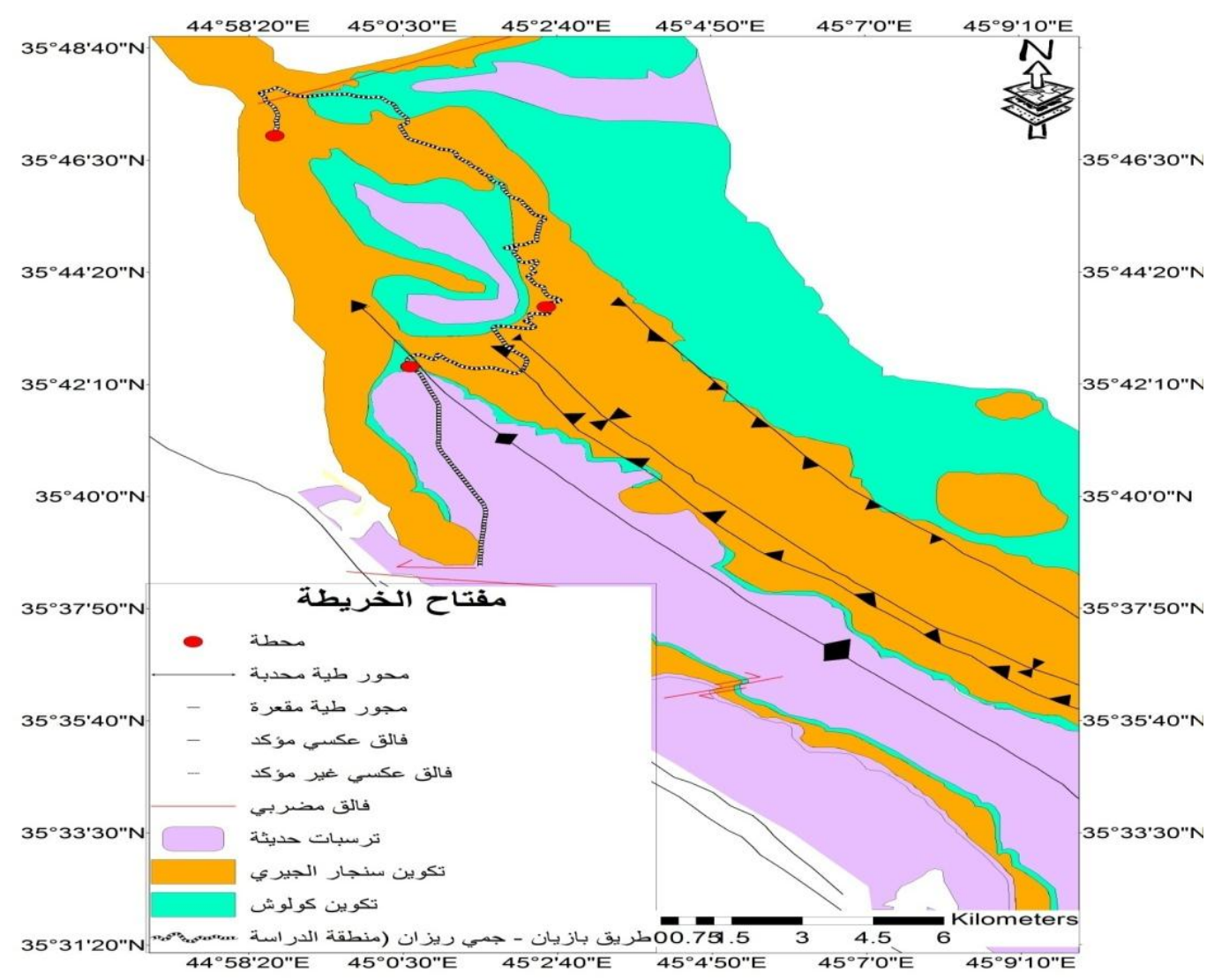

الثكل 2: الخربطة الجيولوجية لمنطقة الدراسة والمناطق المجاورة لها، عن .(Al-Hakari, 2011) 


\section{طرائق البحث}

لقد مرت هذه الدراسة بثلاث مراحل وكما يلي :-

1-مرحلة العمل الحقلي: وقد تم خلالها تحديد مواقع الانهيار الانقلابي التي تكون ممنلة لأنواع الانقلاب الصخري في المنطقة، ونم قياس اتجاه وزاوية ميل المنحدر وارتفاعه عن قدمها وطول وجهه وتحديد عدد الطبقات الصخرية المنكثفة في وجه المنحدر لكل محطة. هذا وقد تمت دراسة وتحليل عدد مجاميع الانقطاعات الصخرية وتم وصف كل مجموعة من تلك الانقطاعات وكل طبقة صخرية وصفاً جيولوجياً هندسياً وذلك حسب (NZGS, 2005). وقد حددت الكتل المنقلبة و /او الآيلة للانقلاب خلا هذه المرحلة وقد وثقت بصورفوتوغرافية واخيراً تم اخذ نماذج صخرية من الطبقات لغرض اجراء الفحوصات المختبرية اللازمة عليها. 2-مرحلة العمل المختبري: خلال هذه المرحلة تم اجراء فحص التحميل النقطي لتحديد المقاومة الانضغاطية اللامحصورة للنماذج الصخرية وبواقع ثلاث نماذج من كل طبقة صخرية منكثفة في وجه المنحدر ولكل محطة. وقد استخدم لهذا الغرض جهاز فحص التحميل النقطي الرقمي موديل (A125N)( وهو جهاز ايطالي المنشأ من صناعة شركة (MATEST). 3-مرحلة العمل المكتبي: تم تصنيف المنحدرات الصخرية اعتمادا على (Al-Saadi, 1981) هذا التصنيف يوضتح علاقة وضعية الطبقات الصخرية مع اوجه المنحدرات الصخرية. وقد تم رسم المساقط الفراغية المجسمة للمحطات خلال هذه المرحلة وذللك باستخدام برنامج Dips 5.1 حيث تم تمثيل مستويات التطبق واوجه المنحدرات ومعدل اقطاب الانقطاعات الصخرية فيها وذلك لتحديد الانقلاب الصخري الحاصل والمحتمل في المنطقة. وتمت مقارنة النتائج مع الدراسات السابقة التخصصية كدراسة (Evans, 1981) و (توكمجي، 1994) و (Wyllie and Mah, 2004)، كما وتم تحديد ادوار الانقطاعات الصخرية (الفواصل وأسطح التطبق) في الانقاب الصخري وكما جاء في (Al-Saadi, 1981 and1991).

\section{تحليل الانهيارات الصخرية في منطقة الاراسة}

قبل البدء في دراسة المنحدرات الصخرية لابد من التعرف على بعض الرموز والاشكال التي استخدمت في المساقط الفراغية المجسمة للمحطات وكما هو موضح في (الجدول 1). 
الجدول 1: يبين الرموز والاشكال المستخدمة في المساقط الفراغية المجسمة للمحطات عن

.(Al-Saadi,1981, 1991)

\begin{tabular}{|c|c|c|c|}
\hline الدلالة & الزمز & 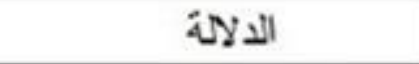 & الرمز \\
\hline معدل اقطاب الفواصل & a & الائرة العظمى لمعذل & \\
\hline & $\underline{\theta}$ & & \\
\hline لنتصوير الامامى & 11 & وضعِيه & \\
\hline اتجاه التصوير الجانبي & ج' & المنحذر المعلق & \\
\hline الاحقلاب الصخري المحتمل & & الاتقلاب الصخري الحاصل & \\
\hline
\end{tabular}

المحطة 1:

تقع هذه المحطة ضمن الاحداثيات (30.6 N (1014متراً) فوق مستوى سطح البحر كما في (الشكل 1). بمتاز الجزء العلوي من المنحدر وبارتقاع حوالي (4/متار ) منه بكونه منحدراً رأسياً وذلك بمعدل اتجاه وزاوية انحدار ( $195^{\circ}$ (1900) كما في( الثكل 3 ) بينما ينحدر الجزء السفلي منه وبارتفاع حوالي (3 امتار) بمقدار (130/190). يصل الارتفاع الكلي للمنحدر في هذه المحطة الى (7امتار) فوق قدمه وعرضه (22 متراً) على طول وجهه. تتكثف في وجه المنحدر مجموعة واحدة من الطبقات الصخرية الجيرية وذلك بمعدل وضعية ( $\left.265^{\circ} / 11^{\circ}\right)$ كما في(الثكل 3) وبذلك فانها تصنف حسب (NZGS, 2005)على انها ذات ميل معتدل (Gentle inclined). تم تصنيف المنحدر في هذه المحطة حسب (Al-Saadi, 1981) كما في (الجدول 2).

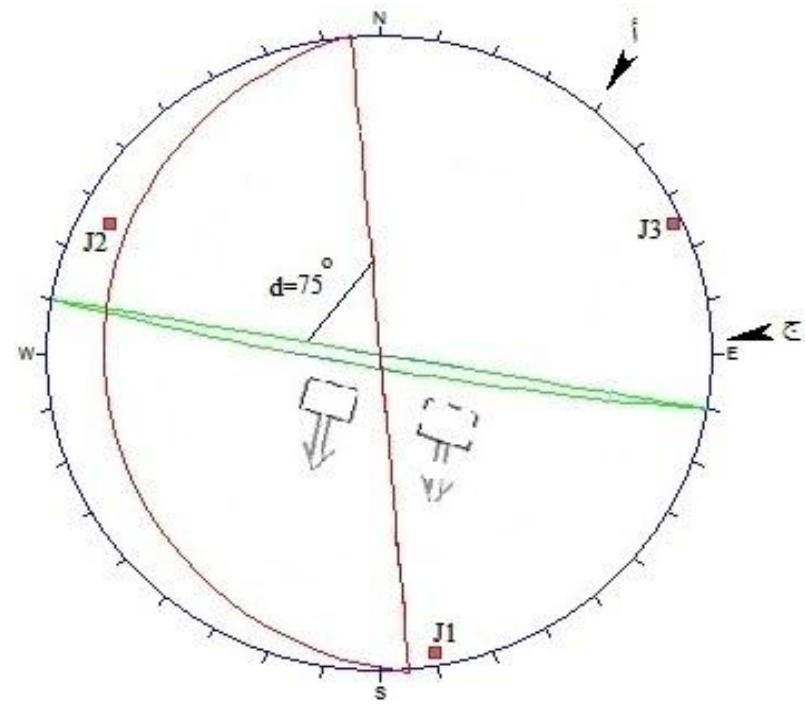

الشكل 3: الاسقاط الفراغي المجسم للمحطة1. 
الجدول 2: تصنيف المحطة 1حسب (Al-Saadi, 1981).

\begin{tabular}{|c|c|}
\hline الوصف & الخاصية \\
\hline ذات انحراف متعامد(orthogonal) حيث إن زاوية الانحراف (d=750) & 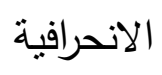 \\
\hline غير متوافقة (discordant). & التوافقية \\
\hline ذات بروز يميني (right emergent). & الجانبية \\
\hline
\end{tabular}

ييلغ السمك الكلي لمجموعة الطبقات الصخرية في هذه المحطة بحوالي (4امتار) وتتميز بالخواص الجيولوجية الهندية التالية والمبينة في (الجدول 3).

الجدول 3: الخواص الجيولوجية الهندسية حسب (NZGS, 2005) لمجموعة الطبقات الصخرية المنكثفة في المحطة1.

\begin{tabular}{|c|c|}
\hline الوصف & الخاصية \\
\hline برثقالي مائل الى الرصاصي & اللون \\
\hline السطح الخارجي للصخرة ذو تجوية منوسطة الى طفيفة & 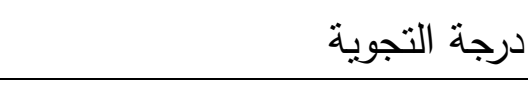 \\
\hline كتلي massive & 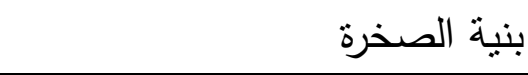 \\
\hline |1.3-0.6 متر ) أي إنها طبقات سميكة & السمك (متر) \\
\hline أي إنها صخور قوية جداً ( $\sigma c=120.54$ MPa) & المقاومة الانضغاطية اللامحصورة \\
\hline Limestone & اسم الصخرة ال \\
\hline
\end{tabular}

ومن الجدير بالذكر انه في الجزء الجنوب الثرقي من وجه المنحدر في هذه المحطة نتكثف طبقة ذات لون اخضر غامق واعتمادا على التصنيف الجيولوجي الهندي للكتل الصخرية الواردة في , NZGS, (2005 تمتاز تلك الطبقة بانها ذات سمك يصل الى (10سم) اي انها نحيفة بأعتدال، وهي ذات تجويـة عالية، ضعيفة القوة (مقاسة حقلياً بالمطرقة الجيولوجية) وهي من صخور المارل، وبقل سمك صخور المارل تلك باتجاه وسط المحطة ومن ثم تتعدم في الجزء الشمال الغربي منها. أظهرت الدراسة التقصيلية للفواصل في هذه المحطة بأنها تتظظم في ثلاث مجاميع كما في (الشكل 2) وتتميز الانقطاعـات الصـخرية (مجاميع الفواصـل وسـح التطبق) في هذه المحطـة بـالخواص الجيولوجيـة الهندسية الموضحة في (الجدول 4). 
الجدول 4: الخواص الجيولوجية الهندية حسب (NZGS,2005) لمجموعتي الفواصل في المحطة1.

\begin{tabular}{|c|c|c|c|c|}
\hline سطحالتطبق & مجموعةJ3 & مجموعةJ2 & Jجموعة Jجمة & الخواص \\
\hline$(265 / 11)$ & $(245 / 88)$ & $(117 / 84)$ & $(350 / 87)$ & معدل الوضعية \\
\hline \multirow{3}{*}{ أي إنها مسافات واسعة } & (0.45-0.45 مثراً) أي & (2.1-0.35 مثراً) أي إنها & (0.40-0.45 متراً) أي & المسافة|البينية (متر) \\
\hline & إنها مسافات واسعة & مسافات واسعة باعتدال إلى & انها مسافات واسعة & \\
\hline & باعتدال & مسافات واسعة جدا & 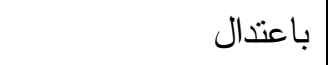 & \\
\hline & بحدود (1.5 متراً) & تصل الى (5 امتار ) & حوالي(0.35 متراً) & الامتدادعلسطحالتطبق \\
\hline --------- & & & & (متر) \\
\hline ذو سطح متموج خشن & ذو سطح مستوٍ خشن & ذو سطح مستوٍ خشن & ذو سطح مستوٍ خشن & طبيعةالسطح \\
\hline مغلقة (لاتوجد فتحة) & (0.2 ملم) مغلقة & (0.5 ملم) مغلقة & مغلقة (لاتوجد فتحة) & الانفتاح \\
\hline----------- & معدن الكالسايت & معدن الكالسايت & معدن الكالسايت & الامتلاء \\
\hline
\end{tabular}

تعتبر الكتل الصخرية في هذه المحطة مستقرة من الناحية التركييية اذ انه عند تطبيق معادلة نسبة

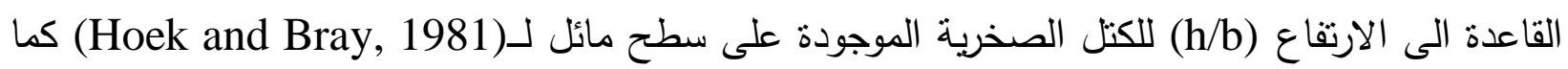

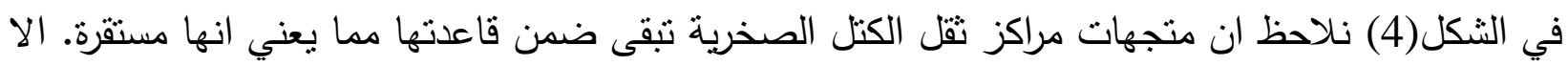
ان كون المنحدر ذو وضعية رأسية فيتعرض وجهه الى عمليات تجوية وتعرية تفاضلية لا سيما في الجزء

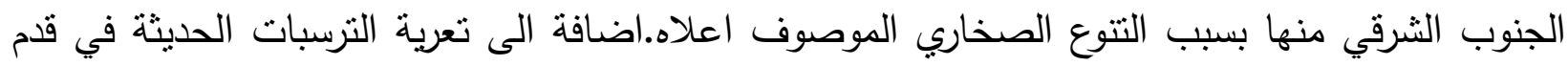
المنحدر وكل ذلك تسبب في ازالة الاجزاء الساندة لتلك الكتل الصخرية وبالتالي نسبب في ميلان تلك الكتل مما يؤدي الى خروج متجه مركز نقل تلك الكتل خارج قاعدتها وبذللك يلاحظ حصول انقلاب ثانوي للكتلة الصخرية (أ) الموضحة في اللوحة (1) وذللك باتجاه (1950) وذلك بميكانيكية انقلاب مشابهة لميكانيكية

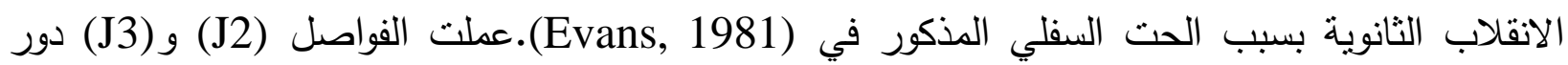
اسطح انطلاق جانبي والفواصل (J1) دور سطح انطلاق خلفي وسطح النطبق دور سطح قاعدي للانقلاب.

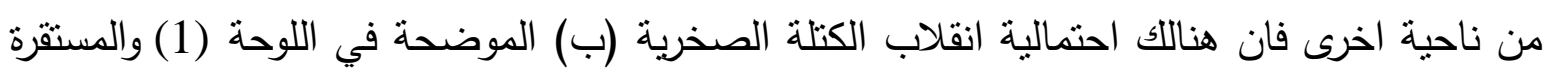

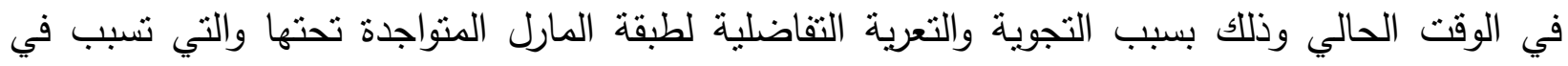
ميلانها وبالتالي خروج متجه مركز تقلها خارج قاعدتها.الثنكل الهندسي للكتلة الصخرية الممثل بزيادة ارتفاعها مقارنة بطول قاعدتها له دور مساعد في خروج متجه مركز النقل خارج القاعدة حتى وان لم يصل

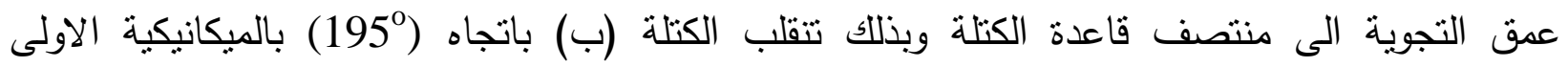

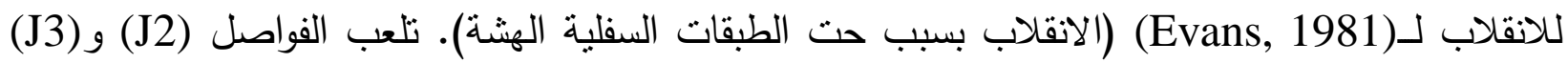
دور أسطح انطلاق جانبية والفواصل (J1) دور أسطح انطلاق خلفية وتكون أسطح النطبق سطح قاعدي للانقلاب. اما بالنسبة للكتلة الصخرية (ج) الموضحة في اللوحة (1) فانها مستقرة في الوقت الحالي وربما لفترة اطول من الكتلة (ب) اذ ان الكتلة (ج) تقع في الجزءالثمال الغربي للمحطة الني لايظهر فيها التباين 
الصخاري وبالتالي تقل درجة التجوية والتعرية التفاضلية فيها بالاضافة الى شكلها الهندسي كما في الثكل (3) اذ ان نسبة القاعدة الى الارتفاع تقريبا نساوي واحد وبذلك تتطلب تجوية السطح القاعدي الى منتصفها او اكثر لكي تخرج متجه دركز تقلها خارج قاعدتها.

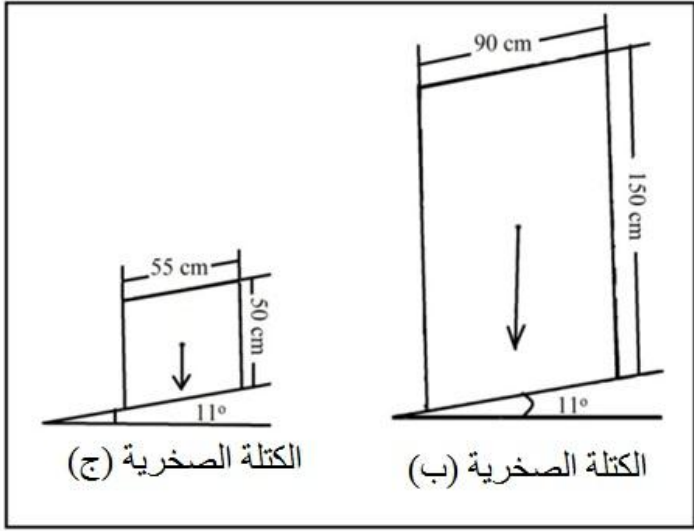

الثكل (4): يبين الثكل الهندسي لبعض الكتل الصخرية في المحطة 1.
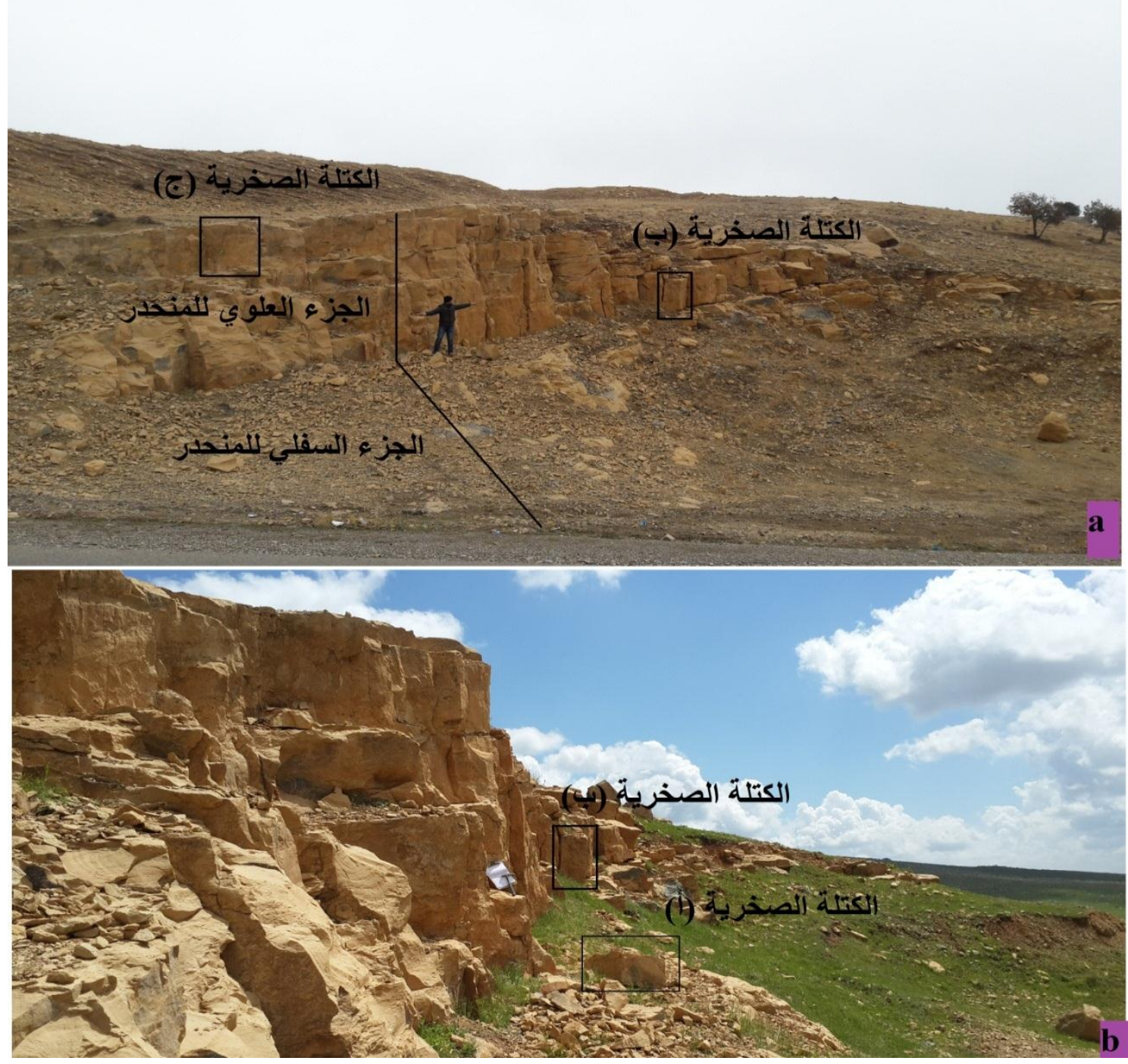

لوحة 1 :منظر عام للمحطة:a) منظر امامي للمحطة، b)منظر جانبي للمحطة. 
المحطة 2:

تقع هذه المحطة ضمن الاحداثيات (35) (الشكل 1). تضـم هذه المحطـة منحدراً يمتاز بكونـه معلقاً (overhanging-OH) وذلك بمعدل وضعية (234/86-OH) كما في الشكل (5). يصل اقصى ارتفاع للمنحدر الى(3.0 متر ) فوق قدمه ويمتد عرضـه لمسـافة (5.5متر) على طول وجهه. نتكثف في وجـه المنحدر مجموعـة واحدة مـن الطبقات الصـرية

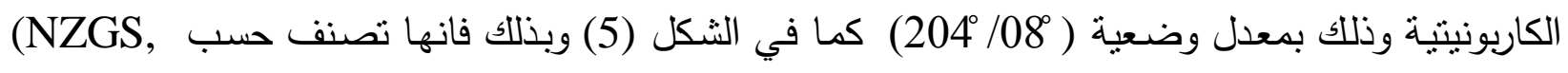
(2005 على انها ذات ميل معتدل (Gentle inclined). يمكن تصنيف هذا المنحدر حسب (Al-Saadi, ) (1981 كما في ( الجدول 5).

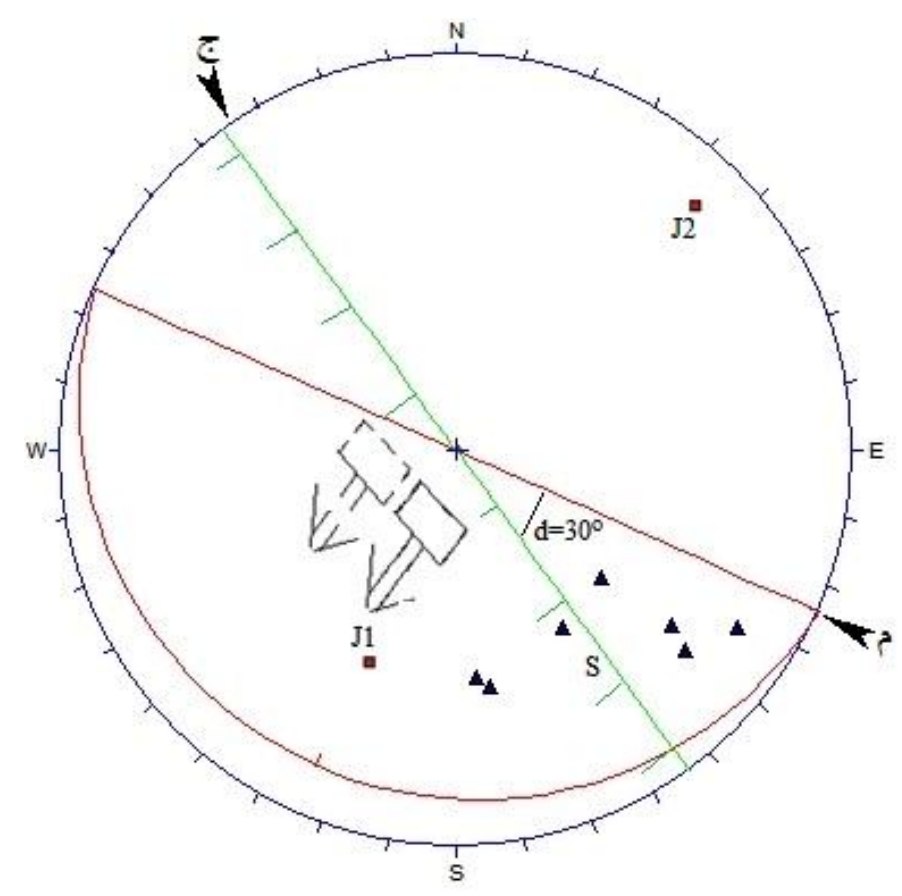

الشكل 5: الاسقاط الفراغي المجسم للمحطة 2.

الجدول 5: تتصيف المحطة 2حسب (Al-Saadi, 1981).

\begin{tabular}{|c|c|}
\hline الوصف & الخاصية \\
\hline ذات انحراف جانبي (oblique lateral) حيث ان زاوية الانحراف (d=30) & الانحرافية \\
\hline متوافقة (concordant) & التوافقية \\
\hline ذات بروز يساري (left emergent) & الجانبية \\
\hline
\end{tabular}


يبلغ سمك الجزء المنكثف لمجموعة الطبقات الصخربة في هذه المحطة بحوالي (2منز)، وتتصف بالخواص الجيولوجية الهندسية الموضحة في ( الجدول 6).

الجدول 6: الخواص الجيولوجية الهندسيةحسب (NZGS, 2005) للطبقة الصخريةالمنكثفة في المحطة5.

\begin{tabular}{|c|c|}
\hline الوصف & الخاصية \\
\hline برثقالي شاحب جداً & 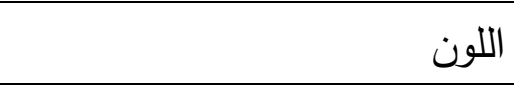 \\
\hline طفيفة التجوية الا في الاجزاء السفلية منها فهي ذات تجوية منوسطة & 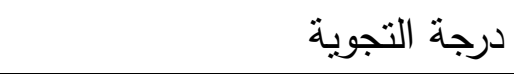 \\
\hline بنية ناعمة & بنية الصخرة الصرة \\
\hline (1.65-1.35متر) وبذلك توصف بانها طبقات سميكة & السمك (متر ) \\
\hline أي إنها صخور قوية جداً (oc =130.68 MPa) & المقاومة الانضغاطيةاللامحصورة \\
\hline LimestoneDolomitic & 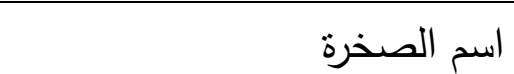 \\
\hline
\end{tabular}

أظهرت الدراسة التفصيلية للفواصل في هذه المحطة بأنها نتنظم في مجموعتين كما في (الشكل 4) وتتميز الانقطاعـات الصـخرية (مجـاميع الفواصـل وسـح التطبقت) بـالخواص الجيولوجيـة الهندسية الموضحة في ( الجدول 7).

الجدول 7: الخواص الجيولوجية حسب (NZGS, 2005)لمجموعتي الفواصل في المحطة 5.

\begin{tabular}{|c|c|c|c|}
\hline سطح التطبق & Jجموعة & J1 & الخواص \\
\hline$(204 / 08)$ & $(224 / 82)$ & $(022 / 60)$ & معدل الوضعية \\
\hline (1.35-65متر ) اي انها & (0.75 متز ) أي انها مسافات & (0.40 - 0.85 منز ) أي انها مسافات & المسافة البينية \\
\hline \multirow[t]{3}{*}{ مسافات واسعة } & واسعة & واسعة باعتدال الى مسافات واسعة & (منر) \\
\hline & اكثر من 5متر & تنتّ لمسافة (0.75 - 1منز ) على سطح & الامتداد على التطبق \\
\hline & & & (متر) \\
\hline خشنة ومتموجة & خشنة ومتموجة & خشنة ومتموجة & طبيعة السطح \\
\hline \multirow[t]{2}{*}{ مغلقة } & 5 بأعندال أي انها فتحات واسعة & بأعتدال & الانفتاح (سم) \\
\hline & ترسبات طينية وقطع صخرية & ترسبات طينية وقطع صخرية & الامتلاء \\
\hline
\end{tabular}


هذا بالإضافة الى تواجد عدد من الفواصل غير النظامية والتي لم تتنضم في مجموعة واحدة وقد رمزت لها بالحرف (S) في (الثكل 5) وكانت ذات وضعيات منتاية مما تعذر قياس مسافاتها البينية وامتداداتها.

تعد الكتل الصخرية في هذه المحطة مستقرة من الناحية التركيبية كما في المحطة (1) وذلك لان

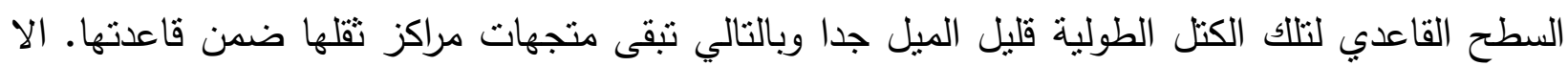

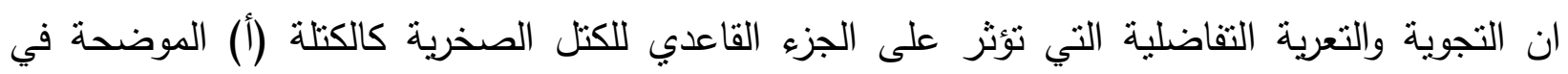
اللوحة (2) عملت على تقتيتها ونحتها وبالتالي سببت في حدوث فراغات وفجوات وبذللك تمايلت الكتلة

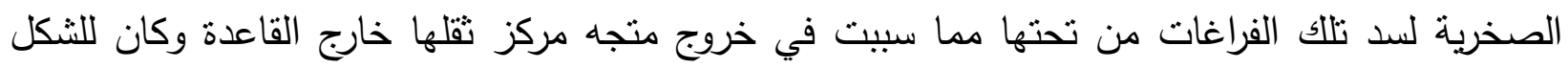

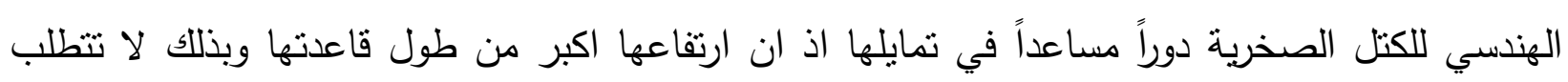

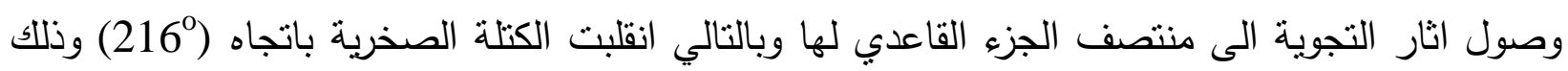
بميكانيكية انقلاب بسبب تجوية وتعرية الجزء السفلي (القاعدي) للكتلة الصخرية نفسها وهذه الميكانيكية مشابهة لما جاء في دراسة (توكمجي، 1994) وقد تلعب الفواصل (J1) دور أسطح انطلاق جانبية والفواصل (J2) دور أسطح انطلاق خلفية بينما يلعب سطح التطبق دور السطح القاعدي للانقلاب. وبذلك فان الفرق في انقلاب الكتل الصخرية في هذه المحطة مع الكتلة الصخرية في المحطة السابقة

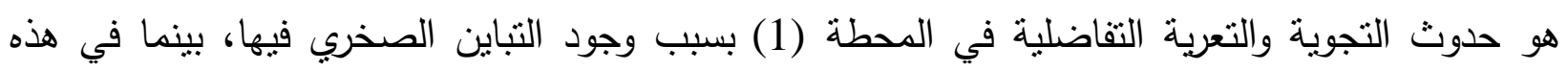
الدحطة نلاحظ شدة ناثير التجوية على الجزء القاعدي للكتل الصخرية منه في الجزء العلوي لها وذلك ربما

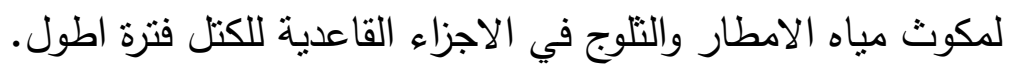

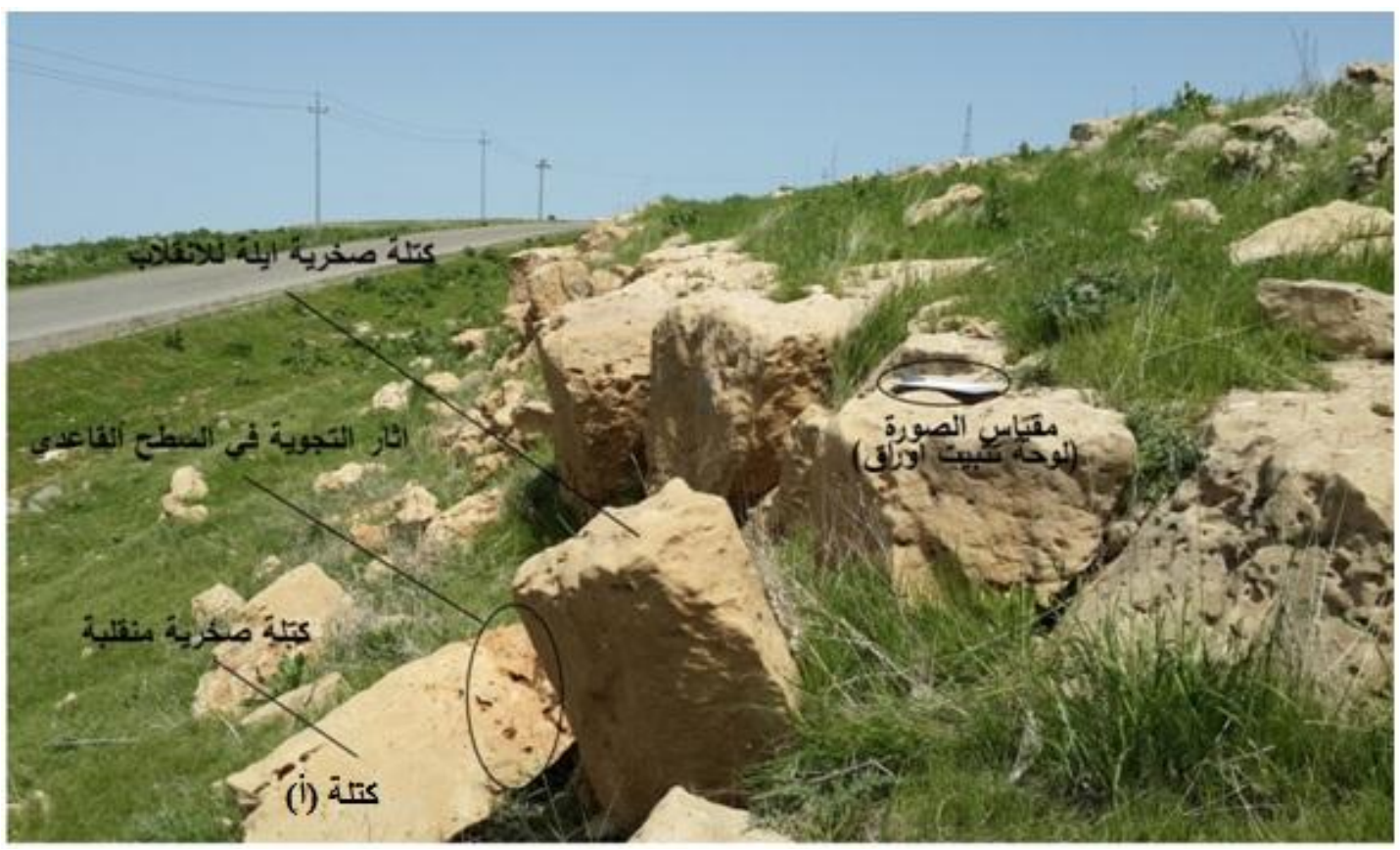

اللوحة 2:منظر الجانب الايمن للمحطة (2) اتجاه التصوير 330. 


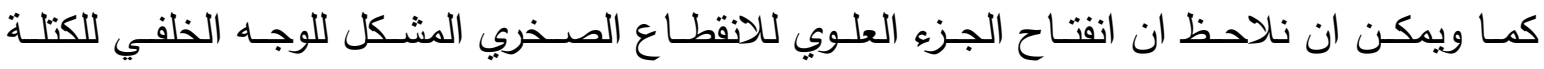
الصخرية (ب) الموضحة في اللوحة (3) و (الثكل 6) اوسع بالمقارنة مـع انفتاح الجزء السفلي له، ويستدل من ذللك على حدوث دوران للكتلة الصخرية حول محور وهمي باتجاه موازي لاتجاه التصوير وذلك بسبب تعرض الحافة الاماميـة للسطح السفلي للكتلة الصخرية لعمليتي التجويـة والتعربـة والتي عملت على تشكيل فراغات وفجوات فيها، ولذلك يحتمل تمايل الكتلة (ب) نحو الامام لسد ثلك الفراغات ومن ثم قد تتقلب وذلك بنفس ميكانيكية انقلاب الكتلة (أ) وبنفس اتجاه انقلابها.

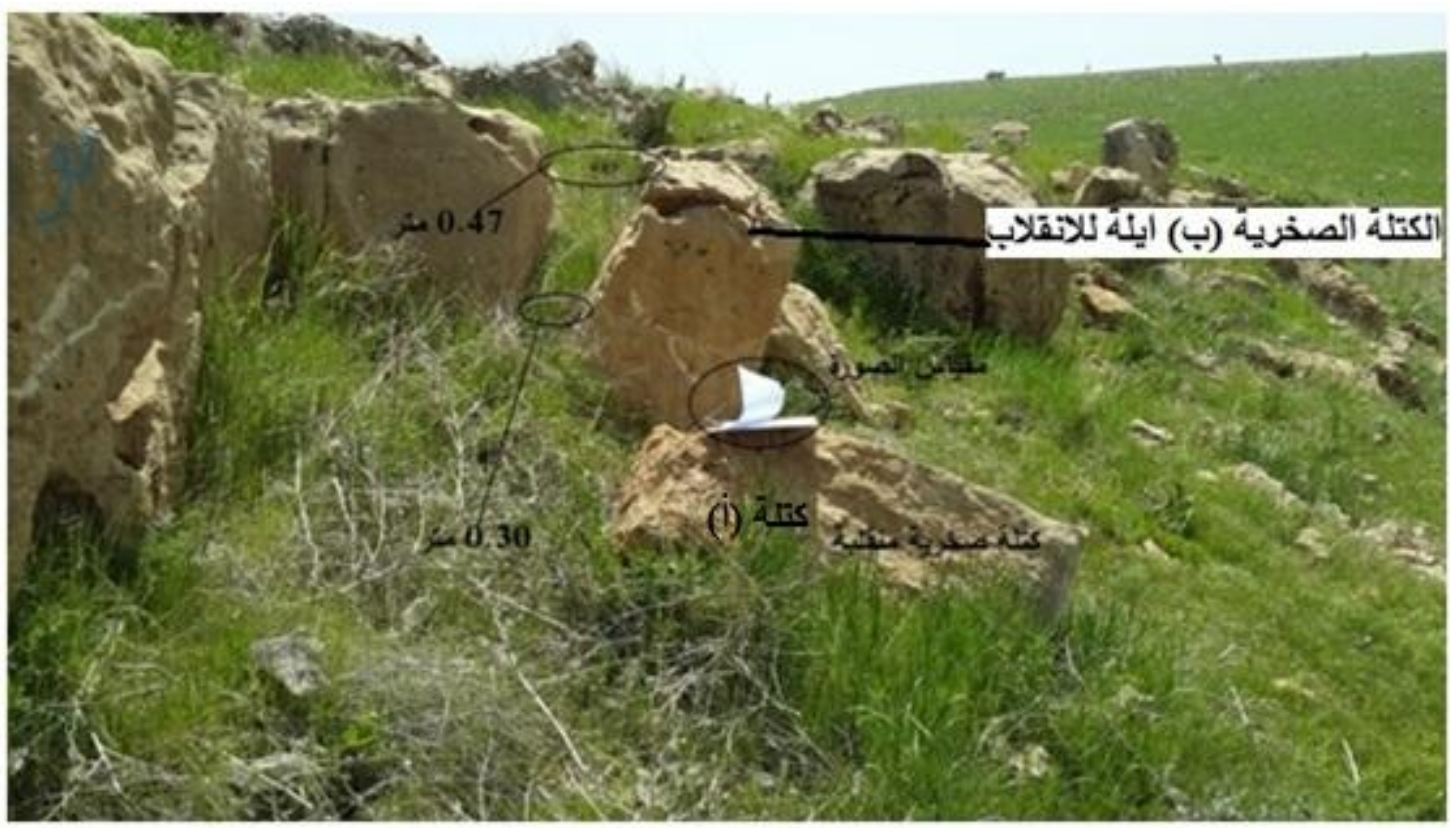

اللوحة 3: منظر للجزء الايمن من المحطة(2): ويظهر فيها الكنلة المنقلبة كتلة (أ)

والاخرى الايلة للانقلاب كتلة (ب).

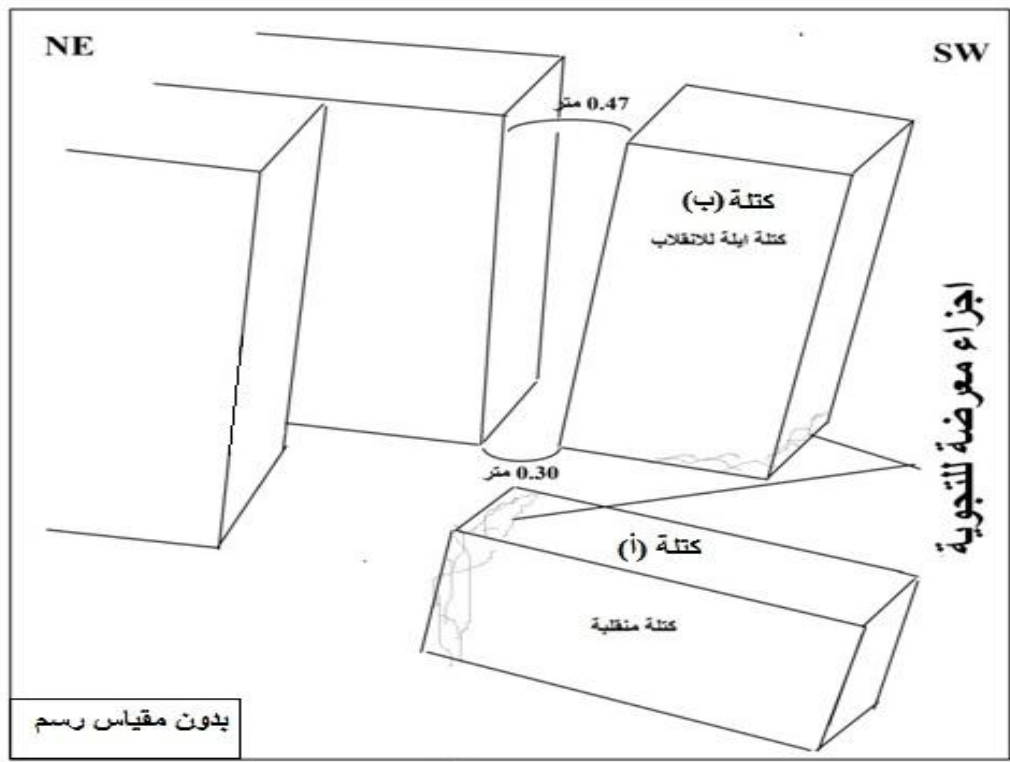

الثكل 6: مخطط توضيحي بالكتل الصخربة في المحطة (2). 
المحطة 3:

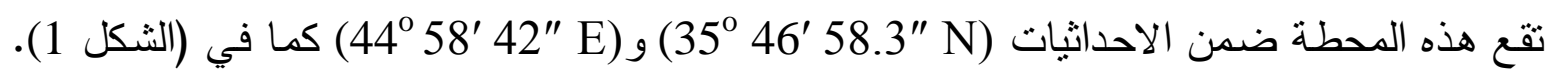

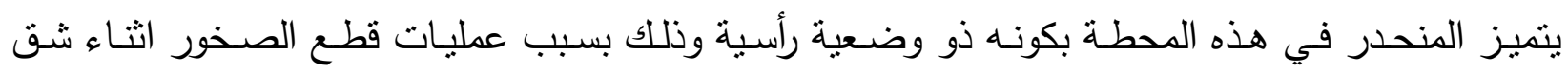

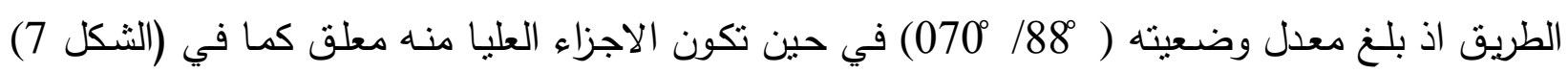
واللوحة (4). يبلغ اقصى ارتقاع للمنحدر حوالي(6.75 متر ) فوق قدمه وتمتد عرضها الى مسافة (5امتار ) على طول وجهه. تتكثف في وجه المنحدرمجوعة واحدة من الطبقات الصخرية الكاربونيتية وذلك بمعدل وضعية (221/09) كما في (الثكل 7) وبذلك فانها تصنف حسب (NZGS, 2005) على انها ذات ميل ونل

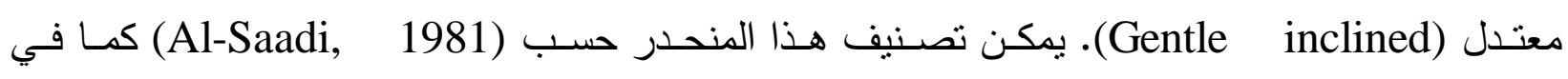

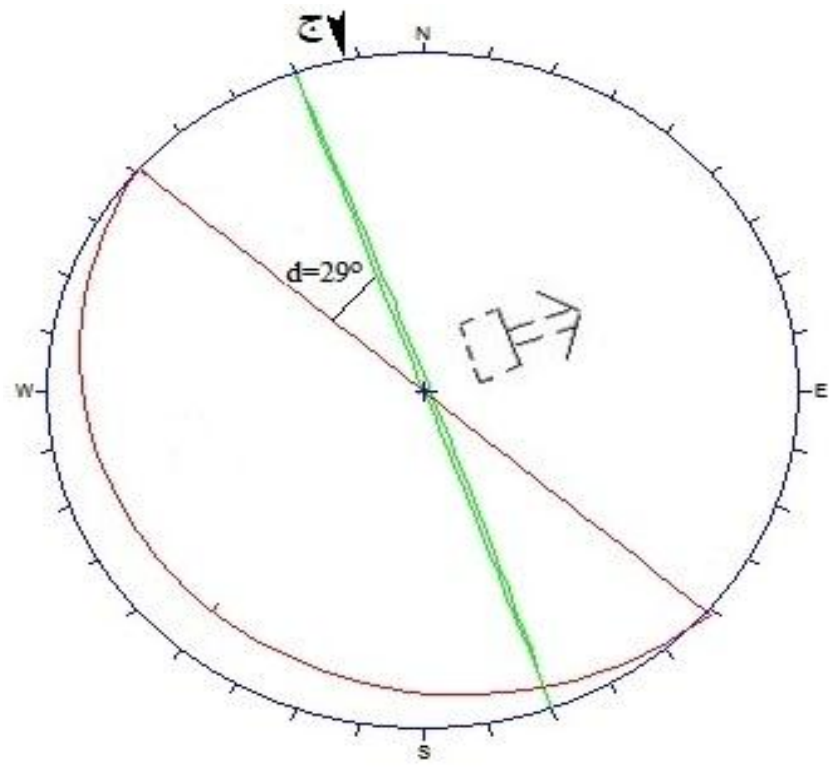

الثكل 7: الاسقاط الفراغي للمحطة(3).

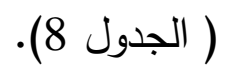

الجدول 8: تصنيف المحطة 3حسب (Al-Saadi, 1981).

\begin{tabular}{|c|c|}
\hline الوصف & 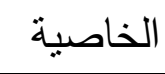 \\
\hline ذات انحراف جانبي(oblique lateral) حيث إن زاوية الانحراف (d=29º) & الاتحرافية \\
\hline غير منوافقة (discordant). & التوافقية \\
\hline ذات بروز يساري (left emergent). & الجانبية \\
\hline
\end{tabular}

يصل السمك الكلي لمجموعة الطبقات الصخرية المنكثنفة في وجه المنحدر (6.5 متر ) وتََصَفِ تلكِ الطبقات بالذواص الجيولوجية الهندسية المبينة بالجدول 9. 
الجدول 9: الخواص الجيولوجية الهندية حسب (NZGS, 2005) لمجموعة الطبقات الصخرية

\begin{tabular}{|c|c|}
\hline & في المحطة (3). \\
\hline الوصف & الخاصية \\
\hline |رصاصي مائل الى الاخضر & 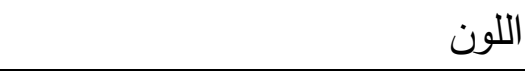 \\
\hline متوسطة في السطح الخارجي للصخرة، ومعدومة بداخلها & درجة التجوية \\
\hline كتلي massive & بنية الصخرة \\
\hline (2 امتار ) أي إنها طبقات سميكة & السمك (منز) \\
\hline أي إنها صخور قوية ( $\sigma c=123.14 \mathrm{MPa})$ & المقاومة الانضغاطية اللامحصورة \\
\hline Dolomitic limestone & اسم الصخرة \\
\hline
\end{tabular}

اضافة الى سطح التطبق فقد لوحظ وجود انقاع صخري بوضعية رأسية الى شبه رأسية يقطع الصخور المنكثفة في هذه المحطة، امتداده على سطح التطبق غير معرف بسبب الترسبات التي تغطيها، وهذا الثق ذو سطح خشن وذو انفتاح حوالي (10 سم) وحاوية على ترسبات طينية، اللوحة (4). نمط الانقلاب المحتمل في هذه المحطة مشابه لنمط الانقلاب في المحطة (2) اي تحدث الانقلاب بسبب تجوبـة وتعربـة الجزء القاعدي للكتلـة الصـخرية، (الشكل 6)، كمـا يتبـين مـن اللوحـة (4) بـان الجزء العلوي للكتلة الصخرية تكون بوضعية معلقة وذلك بسبب تجوية وتعرية الاجزاء السفلى من الكتلة الصخرية وهذا يؤدي الى تمايل الكتل نحو الامـام بسبب الوزن التقيل للجزء المعلق وبالتالي يؤدي الى انقلابها باتجاه

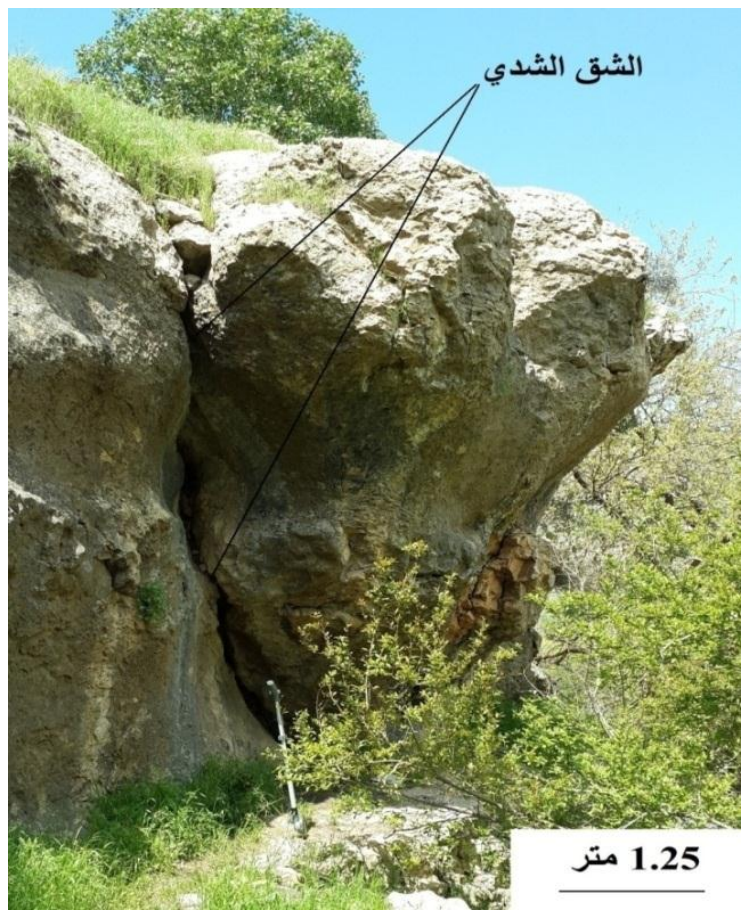

اللوحة 4: منظر جانبي من يسار المحطة 3يظهر فيه شق شدي خلف الكتلة الصخرية. 


\section{الاستنتاجات}

1- ان الميل القليل للسطح القاعدي للكتل الصخرية يجعلها مستقرة غالبا ولكن انترالك العوامل الجيولوجية

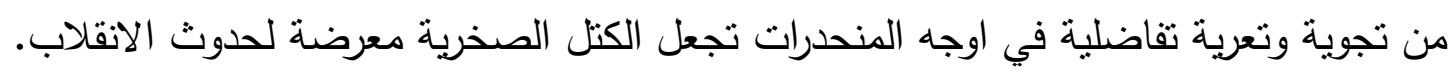
2- لعبت الانقطاعات ووضعياتها دورا اساسيا في تهيئة كتل صخرية قابلة لحدوث الانقله الانلاب الصخري.

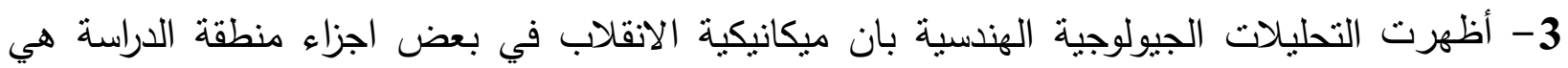
بسبب حت الطبقات السفلى الواقعة تحت الكتلة الصخرية الجيرية، بينما في اجزاء اخرى من المنطقة كانت بسبب تجوية وتعرية الاجزاء السفلية للكتلة الصخرية الجيرية نفسها. المصادر العربية

الدليمي، خلف حسين، 2001. الجيومورفولوجيا التطبيقية، الاهلية للنشر والنوزيع، 273 صفحة. توكمجي، اوميد احمد، 1994. .دراسة جيولوجية هندسية لاستقرارية المنحدرات الصخرية لجبل حمرين الجنوبي (منطقة الصدور)، رسالة ماجستير غير منشورة، كلية العلوم - جامعة بغداد، 126 صفحة. محسوب، محمد صبري، 2001. جيومورفولوجية الاشكال الارضية، كتب عربية للنشر والتوزيع، 318 صفحة.

\section{المصادر الاجنبية}

Al-Saadi, S. N., 1981. A Method for Mapping Unstable Slopes with Reference to the Coast line of S.W. Dyfed, Wales, Unpub. Ph.D. Thesis, University of Bristol. 252 p.

Al-Saadi, S. N., 1991. Composite-Base Toppling of Rock Slopes South of Degala Area NE-Iraq, Journal Sc. Nat., Vol. 1, No. 1A, pp. 35 - 45.

Al-Hakari, S. H. S,, 2011. Geometric Analysis and Structural Evoluation of NW Sulaimani area, Kurdistan Region, Iraq, Unpob. Ph.D. thesis, School of science, University of Sulaimani, $309 \mathrm{p}$.

Bellen R.C., Dunnington, H.V., Wetzel, R. and Morton, D.M., 1959. Stratigraphic Lexicon of Iraq, Lexique Stratigraphque International, Asie (Iraq), CNRS, France, 333p.

Freitas, M. H., 2009. Engineering Geology (Principles and Practice), SpringerVerlag Berlin Heidelberg, 450 p.

Fouad, S.F.A., 2012. Tectonic map of Iraq, scale $1000000,3^{\text {rd }}$ Edition, Iraqi Bulletin of GEOLOGY AND Mining, Vol. 11 No. 1, p 1 - 7.

Hoek, E. and Bray, J.W., 1981. Rock Slope Engineering, $3^{\text {rd }}$ Edition, Institution of Mining and Metallugy, London, $358 \mathrm{p}$.

Jassim, S. Z. and and Goff, J. C., 2006, Geology of Iraq, Dolin, Prague and Moravian Museum, Brno, $341 \mathrm{p}$.

NZGS, 2005, Field Description of Soil and Rock, NZ Geotechnical society INC, $38 \mathrm{p}$.

Wyllie, D. C. and Mah, C. W., 2004. Rock Slope Engineering, Civil and Mining, $4^{\text {th }}$ Edition, Spon Press Taylor\& Francis Group, London \& New York, 431 p. 